\title{
Engagement, Technology, and Mathematics: Students' Perceptions
}

\author{
Catherine Attard \\ Centre for Educational Research \\ University of Western Sydney \\ $<$ c.attard@uws.edu.au>
}

\begin{abstract}
Many schools are investing significant funds in technology in the hope that it will address declining engagement with mathematics and improve students' learning outcomes. This paper presents data from two studies and explores students' perceptions of technology use during mathematics lessons and their resulting engagement. Results from the two studies suggest some relationship between the ways in which technologies are incorporated into mathematics lessons, and teacher experience and expertise.
\end{abstract}

Keywords: engagement, iPads, laptops, primary school mathematics, student perceptions

Student engagement with mathematics continues to be a concern in Australia (Attard, 2014; Commonwealth of Australia, 2008; Sullivan \& McDonough, 2007) and internationally (Boaler, 2009; Douglas Willms, Friesen, \& Milton, 2009). Decreased engagement could potentially have wide-reaching consequences that affect our communities beyond the obvious need to full occupations that require the use of mathematics. Students who choose to discontinue their study of mathematics due to disengagement potentially limit their capacity to understand and interpret life experiences through a mathematical perspective (Sullivan, Mousley, \& Zevenbergen, 2005).

One of the most significant influences on student engagement is the teacher and the pedagogical practices employed (Attard, 2012; Hayes, Mills, Christie, \& Lingard, 2006). Amongst the pedagogical practices commonly seen in contemporary mathematics classrooms is the use of a range of technologies, from desktop computers to mobile devices such as iPads. Although standard desktop and laptop computers have been common in schools for several years, the increased popularity of mobile devices has resulted in schools within Australia and internationally investing significant funds in mobile technologies in the hope that their incorporation into learning and teaching practices will better address the needs of contemporary learners and result in deeper engagement and improved outcomes.

Although the use of technologies in mathematics classrooms is explicitly promoted within curriculum documents in Australia (Australian Curriculum and Reporting Authority, 2012; Board of Studies New South Wales, 2012), there is little evidence that a result of technology use is an increase in student engagement. This paper will draw on data from two 
separate studies to explore students' perceptions of technology use and its influence on their engagement in the mathematics classroom. Current literature pertaining to technology and mathematics, and engagement is now provided.

\section{Mathematics and Technology}

Emerging technologies continue to change every aspect of home life and work: the way we communicate, calculate, analyse, shop, make presentations and socialise. "Computer technologies are changing the very ways we think and make sense of the world" (Collins \& Halverson, 2009, p. 11). Many teachers expect the incorporation of computer technology into mathematics teaching and learning to motivate and engage students (Pierce \& Ball, 2009). However, research into their use in mathematics classrooms has revealed some issues that could negatively impact on student engagement as a result of how they integrate with existing pedagogies. Current curriculum documents express the expectation that such technologies are integrated into lessons, and although there is a significant body of research exploring teachers' perspectives regarding computers and mathematics (Goos \& Bennison, 2008; Hoyles et al., 2010; Thomas \& Chinnappan, 2008), there has been little research on their impact on student learning and engagement.

Some teachers who regularly incorporate traditional ICTs such as desktop or laptop computers into their lessons tend to use them in a way that resonates with a didactical, teacher-centred approach.

\footnotetext{
The traditional methods of teaching mathematics seem to have such a strong hold that the computer's position as an agent of change is relatively weak. Instead, it seems that the computer is assimilated into existing math teaching traditions as regards both content and form (Samuelsson, 2007, p. 11).
}

Other teachers who have successfully implemented computer technology were found to display a wide variety of teaching styles that included a willingness to become a learner alongside students, and a willingness to lessen teacher control in the classroom (Thomas, Tyrrell, \& Bullock, 1996). Factors that inhibit teachers' use of computers include issues of access, lack of technical support, and the time it takes for students to learn to use the equipment and software programs, taking away from time learning mathematics (Forgasz, 2006; Hoyles et al., 2010).

The introduction of mobile technologies such as iPads has provided an opportunity to remove some of the traditional barriers to ICT integration as described above. iPads are easy 
to use, provide ubiquitous access to ICT and have a broad range of affordances. There is also a belief that the devices have the potential to address a disparity between the way young people use digital media outside school, and the ways in which it is used within the classroom (Henderson, 2011; Selwyn, Potter, \& Cranmer, 2009). This disparity is described by Selwyn et al. as a 'digital disconnect' between schools and learners. Distinct affordances offered by the iPads when compared to traditional ICTs include their affordability and ubiquitous access, mobility, ease of use, opportunities for more flexible learning spaces and more opportunities for students to author their own work rather than simply consuming the work of others (Ireland \& Woollerton, 2010; Kiger, Herro, \& Prunty, 2012; Melhuish \& Fallon, 2010).

Although they are easier to operate, it should not be assumed that teachers will use iPads or other mobile technologies in "pedagogically innovative and appropriate ways" (Herrington, Mantei, Herrington, Olney, \& Ferry, 2008, p. 419). If they are provided with little or no professional development and limited opportunities for professional dialogue, teachers are less likely to embed new technologies within their practices (Bennison \& Goos, 2010).

Arguably the use of computer technology in the mathematics classroom has the potential to improve students' engagement in a positive way when used appropriately. This literature review now turns to the concept of engagement and provides a clear definition that will be applied to the data informing this paper.

\section{Engagement and Mathematics}

The term engagement is used often by educators when describing students' levels of involvement with teaching and learning, and many definitions of engagement can be found in literature. In this paper, engagement is viewed as a multi-faceted construct that operates at three levels: cognitive, affective and operative (Fair Go Team NSW Department of Education and Training, 2006; Fredricks, Blumenfeld, \& Paris, 2004). On a general level, cognitive engagement relates to the idea of investment, recognition of the value of learning and a willingness to go beyond the minimum requirements. Affective engagement involves students' reactions to school, teachers, peers and academics, influencing their willingness to become involved in schoolwork. Finally operative engagement encompasses the idea of active participation and involvement in academic and social activities, and is considered crucial for the achievement of positive academic outcomes. 
Translated into a mathematics classroom context, engagement occurs when all three facets come together. This occurs when students are procedurally engaged during mathematics lessons and beyond, they enjoy learning and doing mathematics, and view the learning and doing of mathematics as a valuable, worthwhile task, useful within and beyond the classroom (Attard, 2014). In her Framework for Engagement with Mathematics (FEM), Attard includes the use of technology as an important aspect of teachers' pedagogical repertoires where: "technology is embedded and used to enhance mathematical understanding through a student-centred approach to learning" (p. 2).

For the purposes of this paper, the concept of engagement will encompass operative, cognitive and affective engagement, leading to students valuing and enjoying school mathematics and seeing connections between school mathematics and their own lives. A brief overview of the methodologies relating to the three studies informing this paper is now provided.

\section{Methodology}

In order to explore students' perceptions of technology use and their resulting engagement, data is drawn from two separate qualitative research studies. The studies provided access to student focus group, student and teacher interview and classroom observation data. The first study, referred to as Study A, is a longitudinal study conducted over a period of three years. Study A investigated the influences on student engagement with mathematics during the middle years (Years 5 to 8 in Australia). Data was gathered from a group of 20 students, beginning in their final year of primary school in a Catholic primary school located in Western Sydney, and concluding in their second year of high school at a Catholic secondary college also in Western Sydney (Attard, 2013). For this paper, the students' experiences in a one-to-one laptop program during their first year of secondary school will be explored.

The second study which I will refer to as Study B, is a qualitative study exploring the experiences of one teacher and his Year 3 class group using iPads in mathematics lessons during a six-month iPad trial at a government primary school in Sydney (Attard \& Curry, 2012). At the time, the teacher was in his first year of teaching and was the school's technology coordinator. The teacher had received no professional development to assist in the implementation of the new technology. 


\section{Findings}

\section{Laptops as a central resource: Study A}

In Study A the majority of mathematics lessons were based upon either a traditional text-book accessed via CD-Rom on the students' laptops, or a commercial, interactive mathematics website that the school subscribed to. This was vastly different to the range of resources the participants had been exposed to in the primary school. Although their initial reaction to the constant use of computers was one of excitement, the participants soon reported missing the interactions with each other and with concrete materials, with Kristie's comment reflecting others made by the group: "I think I liked it better when we could handson stuff 'cause I - I think I learn better when we do hands-on stuff 'cause you're actually doing it instead of learning the theory."

The utilisation of a single resource such as the website or textbook for the length of a 100 minute lesson also made it difficult for the students to stay on task and interested in the lesson, with some students admitting to becoming restless and bored. Andrew's comment reflects this sentiment: "after about maybe an hour or so, maybe 70 minutes, me and a couple of my friends get really bored and then we start mucking around and not doing our work cause it's - we just can't stay interested in it. So we muck around and probably not do our work."

The use of computer technology as the central resource for teaching and learning caused initial excitement when the students began Year 7, with Elizabeth commenting: "A good way of how we're learning now is we're getting in touch with technology and we'll be able to do more stuff in the future." However, as a result of the way in which computers were used, the students soon began to experience dissatisfaction with them, finding them distracting and resulting in unfinished class work. The following comment from Samantha reveals the building frustration among the participants:

When we use our Macs on, there's also a lot of distractions 'cause I can see people around, like the boys around me, they're not actually doing their work, they've got games and the calculators on the dashboards and like the internet, and it's like using the Macs, not just in maths but to write, I find it a lot more distracting 'cause there's Bluetooth and I'm very tempted, and the Internet's just there and the teachers aren't on your back a hundred percent there's like a lot of gimmicks where you can just get rid of the screen straight away and go back to your work, like command-H hides that page.

The use of laptops to deliver content by either a textbook or online learning site as the only pedagogy contrasts with the practices promoted in mathematics education literature on 
the use of technology in the mathematics classroom (Thomas \& Chinnappan, 2008). Although the availability of computer technology provided the opportunity for teachers to deliver a new and relevant way of teaching and learning (Collins \& Halverson, 2009), they instead appeared to be used as replacements for teachers. Alison picked up this emerging idea among the students:

\begin{abstract}
Its' probably not the best way of learning because last year at least if you missed the day that they taught you, you still had groups so your group could tell you what was happening. Where now, we've got the computers and it's alright because there is, um, left side of the screen does give you examples and stuff, but if you don't understand it, it's really, hard to understand.
\end{abstract}

It is reasonable to suggest that the website and textbook were not necessarily bad resources. However, the data was showing that it was the way they were used in isolation that meant the students were beginning to disengage from mathematics. The reliance on the computers led to a lack of interaction among students and between teachers and students. By the end of Term 1 many of the participants were displaying negative attitudes with regard to the use of computers in the mathematics classroom.

The limited range of teaching and learning resources implemented during Year 7 appeared to have had a negative impact on the students' attitudes towards and engagement with mathematics. It seemed as though the 'fun' element of mathematics lessons the students had discussed in Year 6 no longer existed.

When interviewed, one of the mathematics teachers who used the laptops as described above discussed his reasons for using the commercial website and text book as his major resources:
We have (the commercial website), which I'm a fan of, we have the text book - I like text books, I'm not just limited to that but they would be my typical lesson. I like the idea where there's an initiation phase, an introduction phase where the kids are actually shown the right way a concept is to be approached, or, even better, the application of a process. There's widgets and things on (the commercial website) which I find excellent. There's also worksheets and all sorts of things that go with that. That's been a pretty good resource.

It is interesting that there is such a broad difference between the teacher's attitude towards those particular resources and the attitudes of the students. This difference in attitude could be attributed to the generational technology literacy gap described by Collins and Halverson (2009) where students' experiences of technology may be significantly more complex than the experiences of the teacher, therefore causing the disparity in the expectations with regard to the use of technology within the classroom. Had the computers 
been utilised in a different manner, for example, then perhaps the students would not have formed negative attitudes towards their mathematics lessons. In defence of the teacher, the structure provided by the commercial website and the text book made it easier for lessons to be planned in a situation where there were no trained specialist mathematics teachers on staff.

Reliance on such resources may have been a safe option when perhaps the Pedagogical Content Knowledge of the teaching staff was not at an adequate level.

The use of computers and text books as the main teaching and learning resource coupled with the teachers' expectations that students work on an individual basis meant students had little opportunity to work together as they had during their primary school years. This discussion will now turn to the experiences of students in Studies B and C.

\section{iPads and Engagement: Study B}

Over the course of the six-month iPad trial, the students and their teacher experienced a range of changes to their mathematics lessons that resulted in a perceived improvement in student engagement. It appears the integration of iPads caused a significant change to the teacher's pedagogical practices which initially relied heavily on the use of worksheets, mathematics investigations and a commercial, computer-based program that provided drill and practice of computation skills. The teacher admitted it was a challenge planning mathematics lessons in terms of sequencing content in an engaging manner:

I am pulling resources from here and there. I am trying to make it coherent; I think that's the hard part when there is no set textbook. So when there is no set textbook, which is great for creative engagement, it is hard to also be like, oh, okay this ties in well with that.

It was the teacher's hope that the integration of iPads would enhance the students' learning by being used as one of a range of tools rather than becoming the focus of each mathematics lesson:

\footnotetext{
...the technology ... it's not everything though, ... it's my attitude, it's how I talk to them, it's how I reflect, it's what I allow them to do as well you know. I'm comfortable with giving them as much as they need as long as you know, it's safe and so, yeah, I'm really willing to test things.
}

At the time of the first focus group discussion the iPads were still regarded as a novelty for the students. When asked to describe their mathematics lessons prior to the introduction of the iPads, a typical response was: "we just had sheets". It appears that immediately following the introduction of the iPads the students began to enjoy their mathematics lessons more, claiming they were more 'fun'. This could be attributed to 
mathematics games the students were playing and it is not possible to conclude if it was purely the game aspect that made the lessons fun or the fact that the students were challenged and actually learned through the games. In one observation, some students were observed to be disengaged from the mathematics whilst still playing a game and interacting with the iPad. Clearly some students were behaviourally and affectively engaged but not engaged on a cognitive level possibly due to a mismatch between their ability and the given task.

Many of the comments made by the students at the conclusion of the trial reflected the perceptions of their teacher. For example, the benefit of instant feedback is reflected in this comment:

Well it makes me feel happy because if you touch it and you make a mistake it just like takes it away, straight away, not like if it is on paper and then it is an exam with no rubbers, if it's on the iPad you can just go oh, that's wrong and you can take it away.

Instant feedback highlights the iPad's potential for building students' confidence in terms of risk taking and feeling safe to make mistakes and try again, building persistence.

There were also several comments comparing the iPads to the use of worksheets, with this comment typical of the group's sentiments: "I think learning with the iPad is better because some children don't concentrate when it's on paper but when it's on an iPad because it's electronic and modern they can concentrate more." However, students could also see a slight disadvantage with using the iPads in that they were aware that they could be distracting, making it difficult to focus and stay on task. This issue highlights the importance of teacher supervision and management skills as well as the importance of being aware of individual students' capabilities.

\section{Conclusion}

Although the data reported in this paper is limited in that it is derived from two small studies, the findings may be beneficial for informing future practice relating to the implementation of traditional or newer mobile technologies. Results from the two studies suggest some relationship between the ways in which technologies are incorporated into mathematics lessons, and teacher experience and expertise. The teacher cited in Study A was not a specialist mathematics teachers and appeared to rely on the technology to support the students' needs. In Study B, the teacher had only one year of teaching experience and was still developing his pedagogical content knowledge. In addition, the iPad technology was very 
new at the time and there was little available professional development or published exemplars of best practice that incorporated the devices.

In Study A, the pedagogies that resulted in lowered engagement were often individual tasks such as the computer-based tutorials or textbook exercises, both of which do not promote interaction and dialogue, and tasks that were perceived to have little relevance to students' lives. Data collected from Study B suggests the integration of the iPads was a success for this particular teacher and group of students. All of the students appear to have had a positive experience and the classroom teacher believed their engagement with mathematics had improved as a result. Advantages of using the iPads include the benefit of mobility, the 'fun' applications (apps) available for students and the high level of interactivity between the student and the technology. It could also be argued that the technology promoted links between school and students' lives outside school, as devices such as iPods, iPhones and iPads are becoming increasingly popular in the home and within the classroom.

The iPads provided an opportunity for the teacher to reflect upon and adjust his pedagogies and although he was already a confident user of the technology, he felt compelled to spend a significant amount of time researching apps for use within the classroom, therefore taking responsibility for his own professional development. Further support in terms of developing his pedagogical content knowledge in relation to technology would have been beneficial, particularly as he was only in his second year of teaching.

In Study A the use of computer technology appeared to be detrimental for these students and their engagement because of the way it was used. There is significant research citing the benefits of using technology to teach and learn mathematics (Goos \& Bennison, 2008; Pierce \& Ball, 2009; Thomas \& Chinnappan, 2008), yet the findings of this study imply that the particular teachers at that school may not have known how to incorporate such technology effectively to enhance learning. The incorporation of a wider variety of interactive, problem-solving based websites, learning objects and other mathematics software through a constructivist approach may have been of benefit and resulted in higher levels of engagement for these students.

\section{References}

Attard, C. (2012). The influence of pedagogy on student engagement with mathematics during the middle years of schooling. In A. L. White \& U. H. Cheah (Eds.), Transforming School Mathematics Education in the 21st Century (pp. 140-157). Penang: SEAMEO RECSAM. 
Attard, C. (2013). "If I had to pick any subject, it wouldn't be maths": Foundations for engagement with mathematics during the middle years. Mathematics Education Research Journal, 25(4), 569-587.

Attard, C. (2014). "I don't like it, I don't love it, but I do it and I don't mind": Introducing a framework for engagement with mathematics. Curriculum Perspectives, 34(3), 1-14.

Attard, C, \& Curry, C. (2012, July). Exploring the use of iPads to engage young students with mathematics. Paper presented at the Mathematics education: Expanding horizons, (Proceedings of the 35th annual conference of the Mathematics Education Research Group of Austalasia) Singapore.

Australian Curriculum and Reporting Authority. (2012). Australian curriculum: Mathematics F-10. Retrieved October 30, 2012, from http://www.australiancurriculum.edu.au/Mathematics/Curriculum/F-10

Bennison, A, \& Goos, M. (2010). Learning to teach mathematics with technology: A survey of professional development needs, experiences and impacts, 22(1), 31-56.

Boaler, J. (2009). The elephant in the classroom: Helping children learn and love maths. London: Souvenir Press Ltd.

Board of Studies New South Wales. (2012). Mathematics K-10 syllabus. Retrieved from http://syllabus.bos.nsw.edu.au/

Collins, A., \& Halverson, R. (2009). Rethinking education in the age of technology: The digital revolution and schooling in America. New York: Teachers College Press.

Commonwealth of Australia. (2008). National numeracy review report. Canberra, ACT: Human Capital Working Group, Council of Australian Governments.

Douglas Willms, J., Friesen, S, \& Milton, P. (2009). What did you do in school today? Toronto, ON: Canadian Education Association.

Fair Go Team NSW Department of Education and Training. (2006). School is for me: pathways to student engagement. Sydney: NSW Department of Education and Training, Sydney, Australia.

Forgasz, H. (2006). Factors that encourage or inhibit computer use for secondary mathematics teaching. Journal of Computers in Mathematics and Science Teaching, 25(1), 77-93.

Fredricks, J. A., Blumenfeld, P. C., \& Paris, A. H. (2004). School engagement: Potential of the concept, state of the evidence. Review of Educational Research, 74(1), 59 -110.

Goos, M., \& Bennison, A. (2008). Surveying the technology landscape: Teachers' use of technology in secondary mathematics classrooms. Mathematics Education Research Journal, 20(3), $102-$ 130.

Hayes, D., Mills, M., Christie, P., \& Lingard, B. (2006). Teachers and schooling making a difference. Sydney: Allan \& Unwin.

Henderson, R. (2011). Classroom pedagogies, digital literacies and the home-school digital divide. International Journal of Pedagogies and Learning, 6(2), 152-161.

Herrington, J, Mantei, J, Herrington, A, Olney, I, \& Ferry, B. (2008). New technologies, new pedagogies: Mobile technologies and new ways of teaching and learning. Paper presented at the Annual Australian Society for Computers in Learning in Tertiary Education Conference, Melbourne.

Hoyles, C., Lagrange, J., Drijvers, P., Kieran, C., Mariotti, M., Ainley, J., . . Meagher, M. (2010). Integrating technology into mathematics education: Theoretical perspectives Mathematics education and technology-rethinking the terrain (Vol. 13, pp. 89-132): Springer US.

Ireland, G.V., \& Woollerton, M. (2010). The impact of the iPad and iPhone on education. Journal of Bunkyo Gakuin University Department of Foreign Languages and Bunkyo Gakuin College(10), 31-48.

Kiger, D, Herro, D, \& Prunty, D. (2012). Examining the influence of a mobile learning intervention on third grade math achievement. Journal of Research on Technology in Education, 45(1), 61-82.

Melhuish, K., \& Fallon, G. (2010). Looking to the future: M-learning with the iPad. Computers in New Zealand Schools: Learning, Leading, Technology, 22(3), 1-16.

Pierce, R, \& Ball, L. (2009). Perceptions that may affect teachers' intention to use technology in secondary mathematics classes. Educational Studies in Mathematics, 71(3), 299-317. 
Samuelsson, J. (2007). How students interact when working with mathematics in an ICT context. Seminar.net - International Journal of Media, Technology and Lifelong Learning, 3(2), 1-13.

Selwyn, N., Potter, J., \& Cranmer, S. (2009). Primary pupils' use of information and communication technologies at school and home. British Journal of Educational Technology, 40(5), 919-932.

Sullivan, P, \& McDonough, A. (2007, July). Eliciting positive student motivation for learning mathematics. Paper presented at the Mathematics: Essential Research, Essential Practice: 30th Annual Conference of the Mathematics Education Research Group of Australasia, Hobart, Tasmania.

Sullivan, P, Mousley, J, \& Zevenbergen, R. (2005). Increasing access to mathematical thinking. The Australian Mathematical Society Gazette, 32(2), 105-109.

Thomas, M., \& Chinnappan, M. (2008). Teaching and learning with technology: Realising the potential. In H. Forgasz, A. Barkatsas, A. Bishop, B. Clarke, S. Keast, W. Seah, P. Sullivan \& S. Willis (Eds.), Research in mathematics education in Australasia 2004-2007:New directions in mathematics and science education (pp. 165-194). Rotterdam: Sense Publishers.

Thomas, M., Tyrrell, J., \& Bullock, J. (1996). Using computers in the mathematics classroom: The role of the teacher. Mathematics Education Research Journal, 8(1), 38-57. 

Southeast Asian Mathematics Education Journal 2014, Vol. 4 No. 1 